\title{
Self-Controlled Electronic Cold Start System - Vehicle TestS DEMONSTRATION
}

\author{
Tadeu Miguel Malagó Amaral \\ Heitor Moreira Cavalhieri \\ Marcos Cardoso Romano
}

Mahle Metal Leve S/A - Tech Center Brazil Jundiaí

Ford Motor Company - FSAO TPG Tatuí

E-mails:tadeu.amaral@br.mahle.com, heitor.cavalhieri@br.mahle.com, mromano9@ford.com

\begin{abstract}
Flexible fueled engines development represents one of the most successful engineering initiatives already implemented in Brazil. It stimulated local engines and fuel technology development in order to conquer market with innovative solutions. However, it is clear that a final solution for cold start phase was missed in the first generation. For this, research on fuel heating system has been done to improve customer satisfaction and overall vehicle response at cold phase. Based on positive temperature coefficient (PTC) thermistor semi-conductor technology and high thermo transfer efficiency, a new cold start system (CSS) concept has been developed. This new technology allows fast and reliable start for flexible vehicles under cold temperatures, without the need of additional electronic control, typically used by current fuel heating systems. This paper presents vehicle tests results of this new technology in comparison to traditional fuel heating system.
\end{abstract}

\section{INTRODUCTION}

In the beginning of 1970 s, oil rationing triggered a need of fuel renewable self-sufficient development in Brazil. Since that time, a package from the government economic and technical incentives for ethanol usage was released and several companies in the fuel and automotive industry were stimulated to develop an ethanol powered vehicle. Due to gasoline high prices and good ethanol vehicle performance, ethanol vehicles succeeded in conquer Brazilian customers. However, as gasoline price reduced and ethanol price changed considerably, ethanol vehicles competitiveness reduced, according to sugar price oscillations in the market. Technological solution developed by automotive industry was the flexible fueled engine. This type of engine can run with ethanol, gasoline or a mixture of these two fuels in different percentages. In this way, decision about which fuel (gasoline or ethanol) would be used was finally at customer hands. Flexible fueled engine has been consolidated as main solution for Brazilian market inside the automotive industry and then the need to convert global engine technology to local flexible fueled configuration.

Moreover, as environment programs take place worldwide, ethanol usage has been boosted by its ecological appeals: made by renewable energy sources and biomass, ethanol contributes to carbon dioxide and greenhouse effect reductions; collaboration for pollutant emissions and high biodegradability property, decreasing contamination of ground and water when 
compared to petroleum fuels. In this way, local flexible fueled technology and ethanol powered engines technologies are now found in different markets like Europe and United States. In these countries part of gasoline has ethanol and anhydrous ethanol can be found in traditional gas stations, while in Brazil part of gasoline also has ethanol and hydrous ethanol (with maximum water content $5 \%$ in volume) is sold at gas stations.

However, since the first carbureted ethanol engine, one of the main ethanol engine issues is related to cold start. Associated with the natural difficulties of cold starting, ethanol properties further contribute to the demerit of fuel atomization thus requiring auxiliary starting devices [1]. In this way, several cold start systems were developed by automotive industry in order to cover this gap.

\section{CURRENT COLD START SOLUTIONS}

In order to surpass engine cold start difficulties caused by ethanol characteristics the most used device is the auxiliary gasoline sub-tank [2]. At this application, when the driver opens the door or when the driver inserts the vehicle key in the ignition switch, the amount of gasoline to be injected is estimated by the electronic control unit (ECU) considering engine coolant temperature, air charge temperature and previously calculated percentage of ethanol in the main tank. At the moment of engine cold crank, this gasoline is pumped from gasoline reservoir to the intake manifold. Incoming air flow allows gasoline (from sub-tank) and fuel from (main tank) mixture to reach the combustion chamber. As gasoline has lower flash point compared to ethanol, it allows first combustions and engine start in cold environments.

Although auxiliary gasoline sub-tank solution is quite simple, it carries customer negative points and technical risks: customer periodic maintenance is needed, as empty auxiliary gasoline sub-tank may forbid the start; if not filled up correctly it may start a fire due to the proximity of the hot engine; sub-tank crash constraints; low precision on the amount of gasoline injection due to the simplicity of the low pressure fuel pump, solenoid valve and nozzles. Such low precision can result in higher pollutant emissions and poor start ability and/or poor drivability.

More recent cold start systems technology consists of heating up ethanol. Once the ethanol is heated, fuel atomization is improved, thus allowing combustion even under environment temperatures below $0^{\circ} \mathrm{C}$. The atomization effect is even noticed visually, as showed on figure 1.

(a)

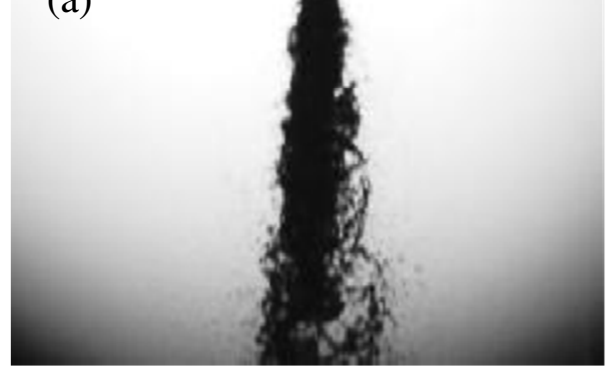

(b)

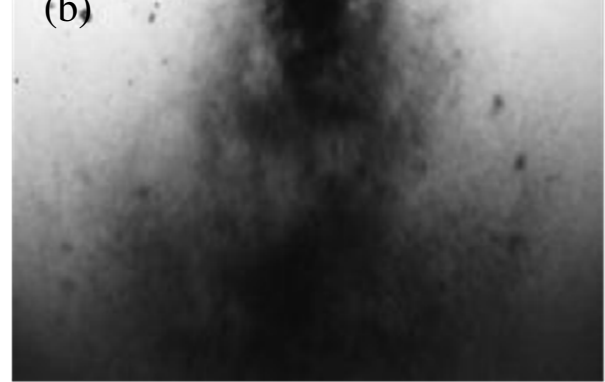

Figure 1. Comparison between injection sprays: low atomization (a), high atomization by fuel heating (b) [3]. 
Some advantages of ethanol heating systems compared to auxiliary sub-tank solution are: more precision on fuel injection during cold start, as there is no need of auxiliary injectors; no need to fill up additional tank with gasoline; lower fire risk, as it does not store gasoline close to the engine and has lower leakage risk; pollutant emissions reduction, because of fuel injection precision and warmed ethanol benefits; reduction of oil dilution by fuel contamination, due to system injection precision and benefits of warmed fuel; consistent start ability and drivability.

Ethanol heating systems face new challenges to predict fuel overheating, because injected fuel temperature must be precise. Some systems, for achieving the ethanol temperature within short time, need electric heaters that can reach over $400^{\circ} \mathrm{C}$ (way over boiling point). Others do not have high thermal efficiency and, for this reason, have to keep low fuel volume stored inside the heater for fast fuel heating, what is a risk of fuel overheating too. If fuel temperature is excessive, fuel bubbles are injected and start could not happen. On the other hand, if fuel is not warmed enough, atomization process does not happen and as consequence the vehicle cannot start. In this way, the system must check electric parameters and correct the heater electric power in real time.

Besides taking in consideration environment conditions and the calibration information stored inside the ECU, the system must consider electric current and power conditions. For instance, battery condition can be different to its rated value because of intensive usage or slightly voltage variation. If the system was designed to work on certain voltage level, the heat transfer balance would be affected and the system will not perform according to the original plan.

Due to this, in order to use fuel heating systems, developers are using an electronic monitoring unit for temperature corrections in real time, protection against overheating and voltage variation compensation. Based on fuel temperature, heating unit information and voltage condition, ideal power is calculated and transferred to the heating units in order to have a good cold start. However, this additional electronic monitoring unit needs additional work for temperature mapping condition (complex temperature model). As there is no direct temperature sensor at final configuration, it needs to be calibrated during engine development stage through indirect characteristics measurement like turned-on/off cycle times. This process leads to longer development time and robustness reduction if the system presents conditions not considered in the calibration phase during real life.

\section{NEW CONCEPT DEVELOPMENT}

Self-controlled electronic cold start system is based on two main principles: PTC thermistor semi-conductor technology and high thermo-transfer-efficiency-body.

Manufactured by polycrystalline ceramic and doped with specific semiconductors, PTC thermistor composition can be customized to produce the desired thermal-electric behavior. As soon as voltage is applied to the PTC thermistor terminals, electric current flows through the component converting electric to thermal power. When PTC thermistor heats, electrical resistance increases, thus decreasing electric current and decreasing heating power by itself (illustrative PTC behavior on figure 2). In this way, a self-temperature-regulation is determined. PTC thermistor maximum temperature can be set during its manufacturing process. This characteristic, together used with an optimized heat transfer body, enables cold 
start high performance and self-fuel-temperature-control without additional electronic controlling.

In this way, a self-controlled-temperature behavior is quite important as direct temperature measurement is done and control signal defined since heat production, eliminating issues due to possible electronic failures, decreasing software (vehicle calibration) and hardware implementation complexity and thus providing high safety against fuel overheating.

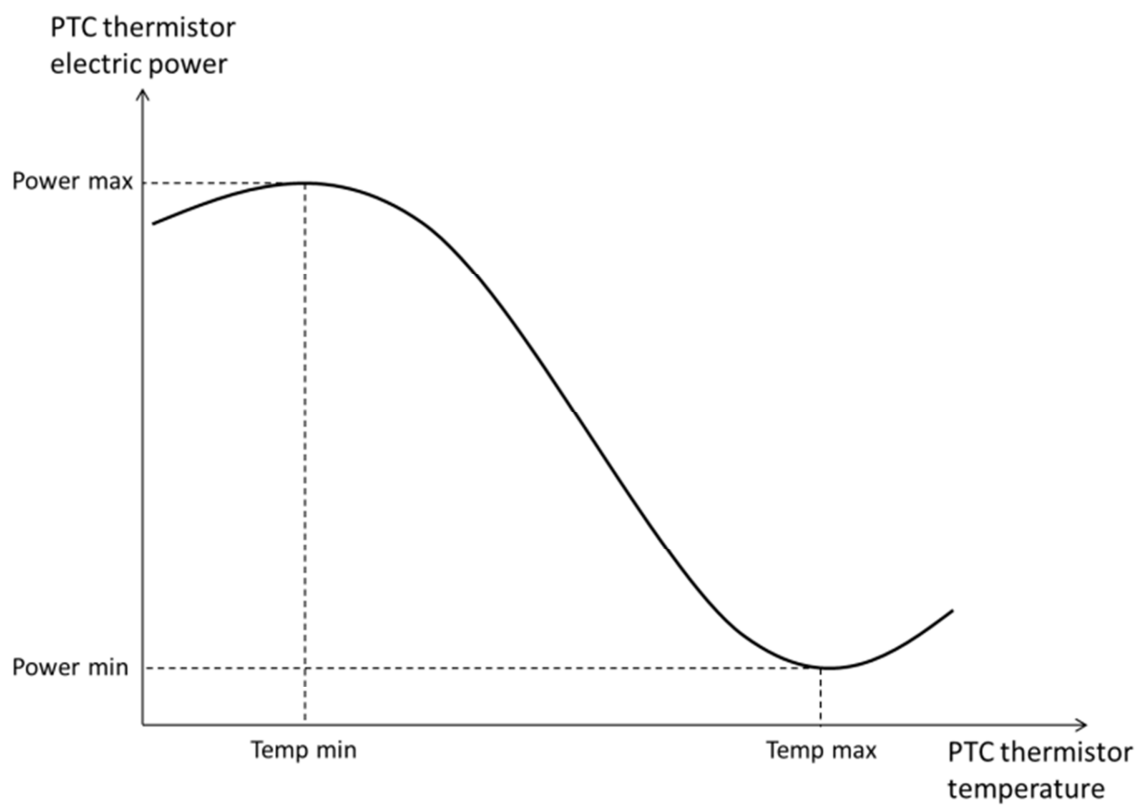

Figure 2. Illustrative PTC thermistor behavior

The high thermo-transfer-area-body (figure 3) is the second key point in the self-controlled electronic CSS. As fuel is a bad heat conductor, fuel around the heat exchanger must be spread as thin fuel layers, allowing fast and homogenous temperature distribution into all fuel volume inside the heater. This fuel volume must be small to provide hot injection at crank phase with short pre-heating time, but in volume enough to allow the vehicle start. High thermo-transfer-area is also important to keep hot fuel injection during post-crank phase (dynamic fuel flow), guaranteeing cold starting under aggressive temperature conditions, good drivability and low pollutant emissions level. The high thermo-transfer-area-body shape is dimensioned to take advantage of liquid flow and assisting the heat transfer from the PTC thermistor to the fuel around the heater exchange, also forecasting convection phenomena inside the fluid. It is important to note that, if such optimizations on heat exchanger contact area and heat transfer were not implemented, it would be needed PTC thermistor with higher maximum surface temperature to compensate the heat transfer deficiency and thus forcing the need of dedicated electronic monitoring unit for avoiding fuel boiling inside the heater. 


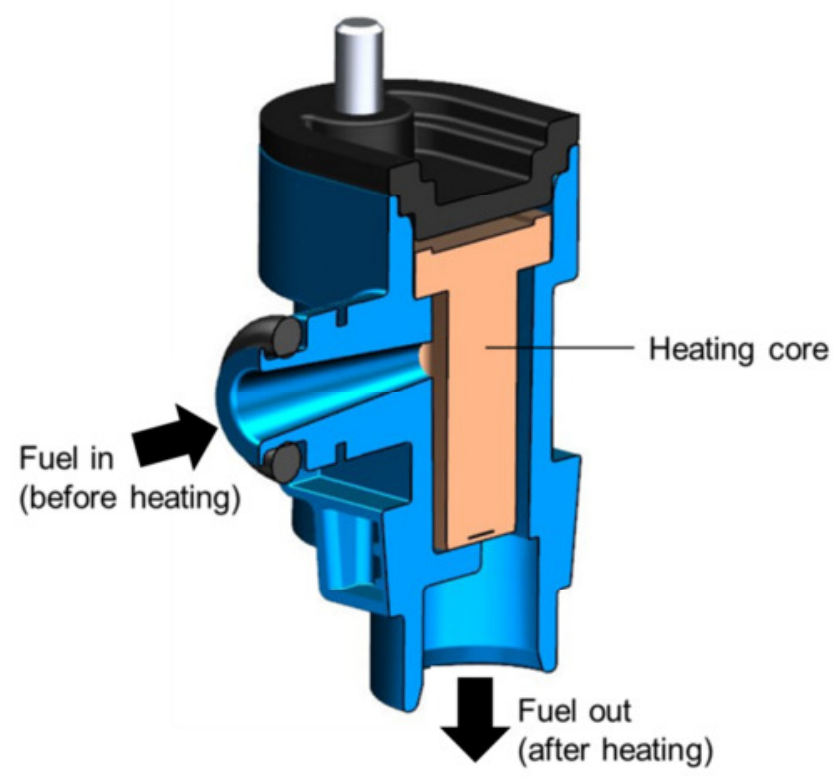

Figure 3. Self-controlled electronic CSS view, highlighting the heating core

The self-controlled electronic cold start system was designed to have reduced size and to be placed as an intermediate component between the vehicle fuel rail and the vehicle fuel injector (figure 4).

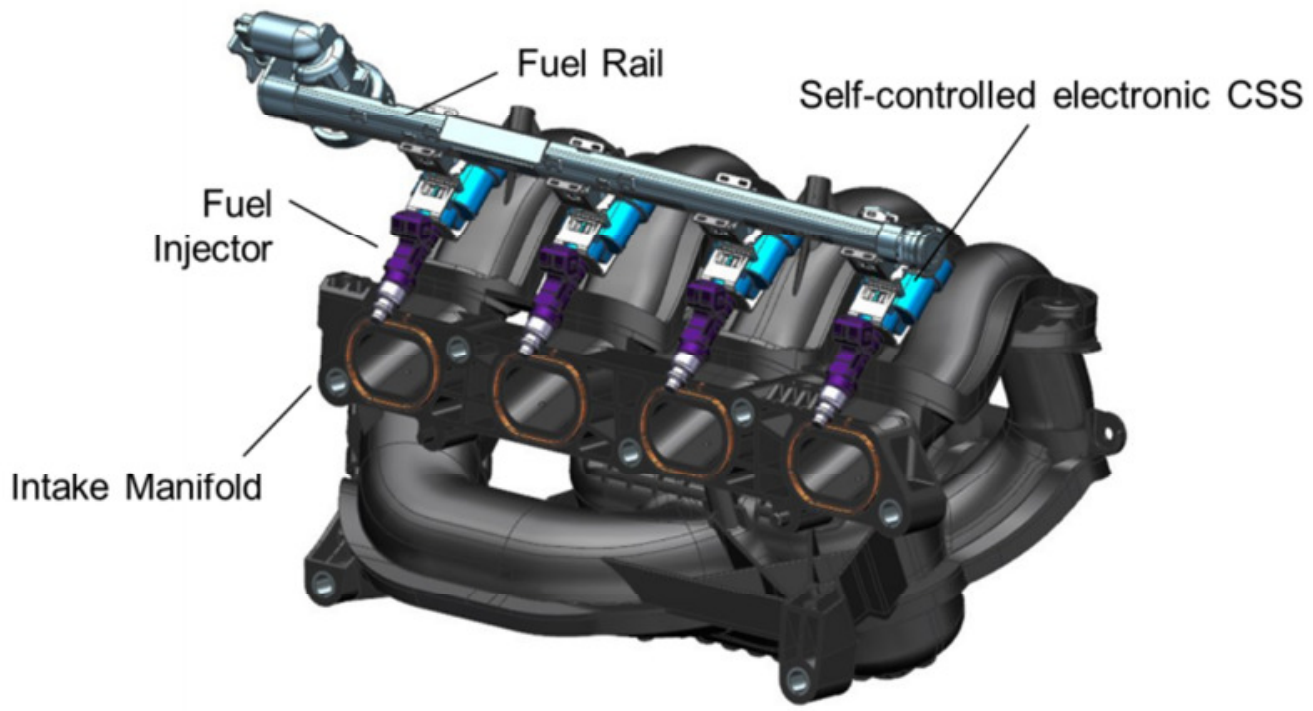

Figure 4. Self-controlled electronic cold start system assembled at illustrative vehicle application

\section{TEMPERATURE MODELING FOR THE SELF-CONTROLLED ELECTRONIC COLD START SYSTEM}

One of the main challenges of heated ethanol cold start systems is the fuel temperature modeling, since a low fuel temperature can hamper the start and too high temperature can result in fuel boiling, leakage or components damage. In this way, cold start vehicle calibration for current heated ethanol systems must be precise and consequently complex.

As self-controlled electronic CSS was projected to have high heat transfer area in compact distribution size inside the heater plus PTC thermistors for electrical energy conversion to 
heat, the system is able to fast heat the fuel inside it with high thermal efficiency. For this reason, the temperature model now does not need to be so precise so that the system provides fuel temperature in ideal conditions for reliable cold starts. Furthermore, an additional electronic control unit is not an obligation any more.

Simple temperature model for self-controlled electronic CSS is shown on figure 5. Using as input engine coolant, inlet air and environment temperatures as references, fuel initial temperature is estimated. Based on environment temperature and fuel flow, heat loss is estimated. Using battery voltage and on-time information, PTC heat gains provide to the system is calculated. The balance of heat gains and losses result in an instantaneous fuel temperature (Temp Fuel Calc), which is compared with the target temperature (Temp Fuel Target). If Temp Fuel Calc < Temp Fuel Target, the system stays on, otherwise it is off. It is important to note that all variables used in the model (ACT, ECT, VBAT, TIME_On and fuel flow) are already present in nowadays flexible vehicles ECU information.

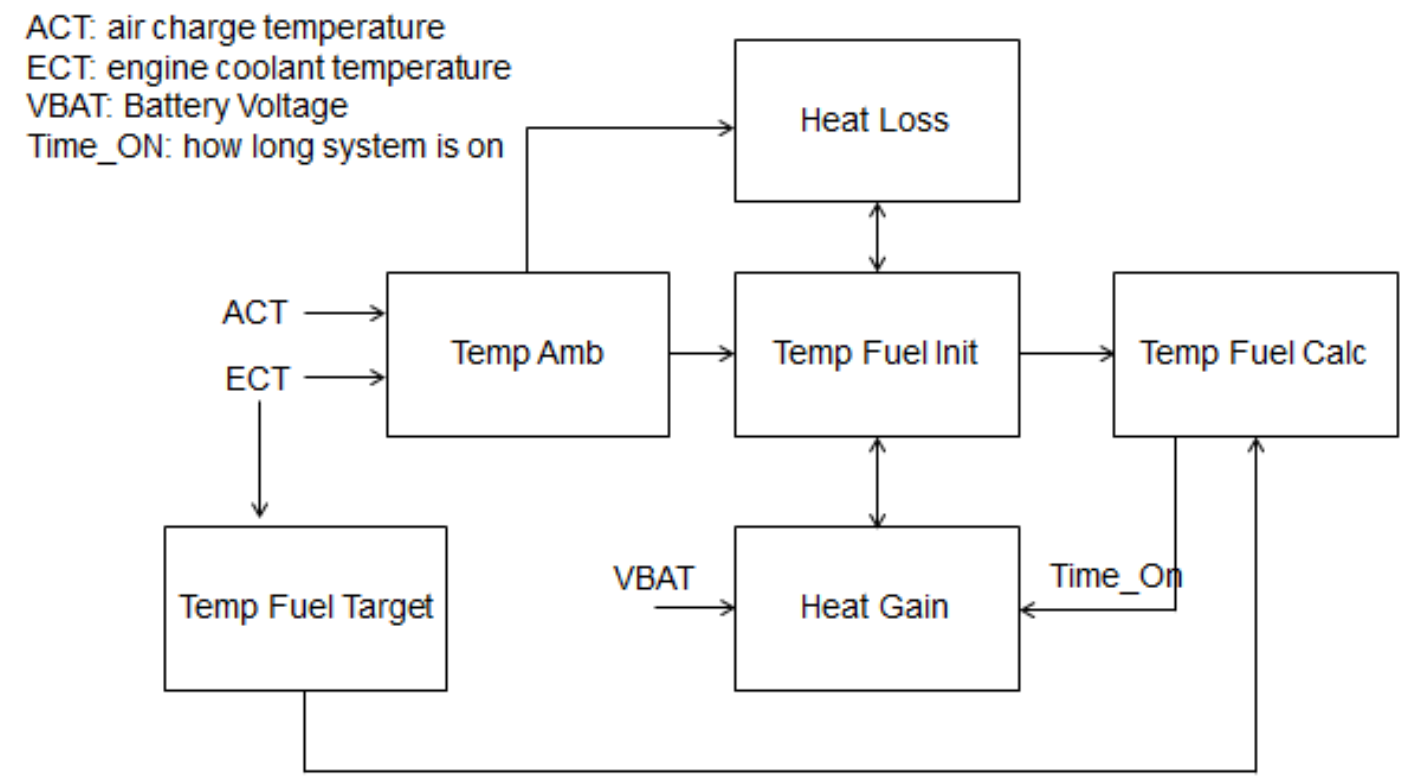

Figure 5. Self Controlled Electronic CSS Temperature Model

\section{VEHICLE TESTS PROCEDURE}

In order to evaluate self-controlled electronic CSS performance, vehicle tests were performed (figure 6). For this, a 1.6L engine with 16 valves and dual variable camshaft timing (VCT) was used. This engine already uses a heated ethanol system with additional electronic heating control unit and is at market with final calibration. This reference vehicle was tested at climatic chamber using same soaking parameters and crank procedures at different temperatures in order to create a baseline study. Afterwards, original heated ethanol system and its electronic control unit were removed. The self-controlled electronic CSS was assembled at the same vehicle. Same procedure was implemented at same conditions used in the baseline measurements in order to allow system comparison. 


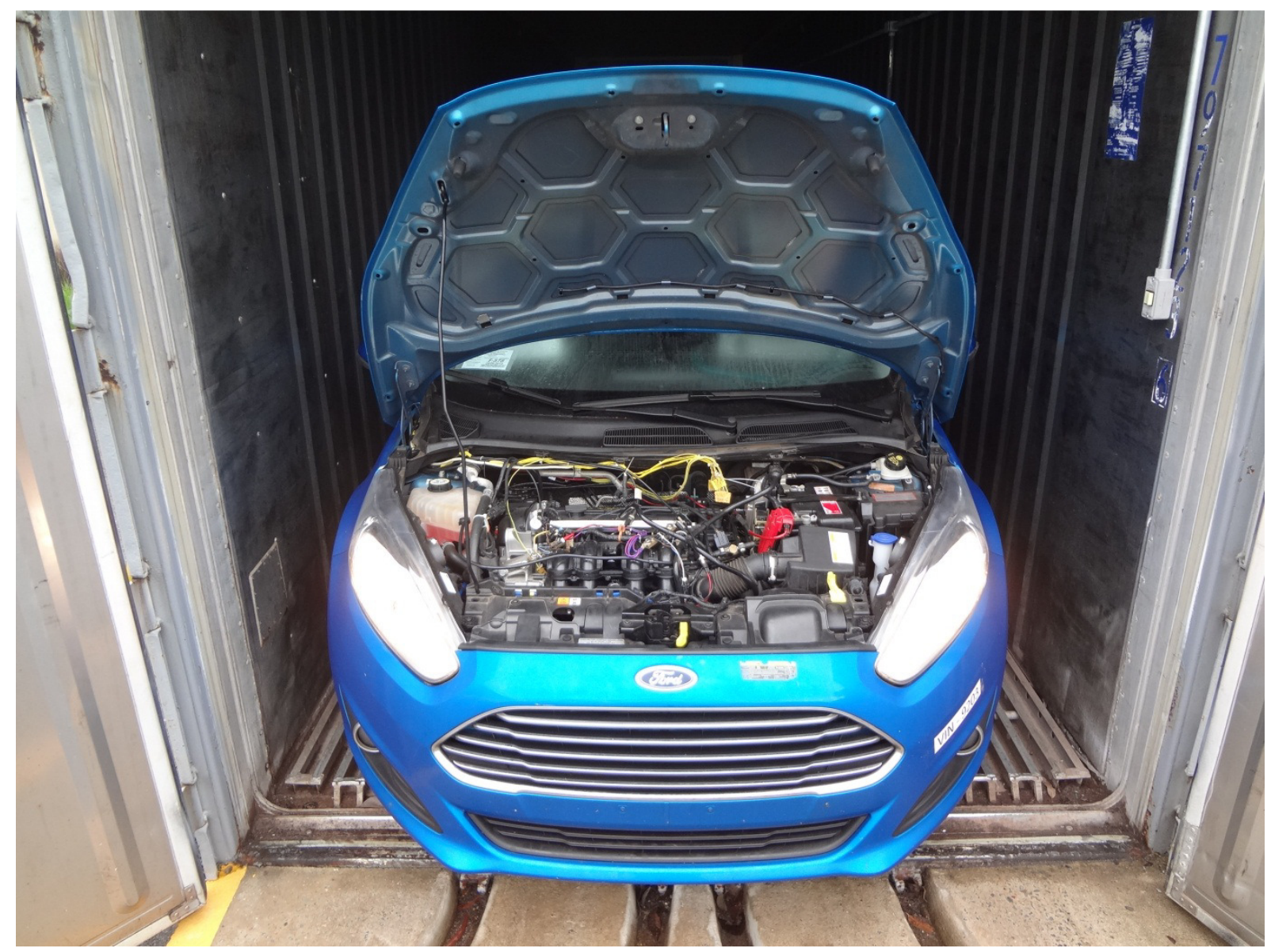

Figure 6. Image of vehicle inside climatic chamber

As test procedure, the vehicle remains at least 6 hours inside a climatic chamber under controlled temperature. Then, a driver cranks the engine and drives around the proving ground, assuring that the vehicle is able to keep drivability after starting. After every test round, the vehicle runs for at least 1 hour in order to purge possible diluted fuel from oil, generated at cold phase and also to recharge the battery. Each system was tested several times in different temperatures. No components modification was made on the car except the replacement of the current cold start heating system (including its electronic control unit), called baseline system, by the self-controlled electronic cold start system. In additional, no change in calibration of ECU was done, meaning that all tests were performed using the already implemented calibration of the original heated ethanol system.

When using heated cold start systems, for product development and calibration strategy construction, it is typically defined three different phases along the vehicle cold start. These phases are below, didactically presented, for further test results comments. During the comparative tests, pre-heating time and start time are acquired for cold quality analysis.

Pre-heating phase: comprised from the moment in which the cold start system begins fuel preheating until the moment that the starter motor begins the engagement. Pre-heating time is the duration of this phase.

Crank phase: comprised from the moment in which the starter motor begins the engagement until the moment that the engine achieves typically 700 revolutions per minute (rpm). At this 
phase, the cold start system must be able to provide fuel hot enough to achieve reliable crank within fast time. Starting time is defined as the crank phase duration.

Post-heating or post-crank phase: comprised from the moment immediate after the engine achieves typically $700 \mathrm{rpm}$ until the end of the heating phase.

The cold start system has an important function during the post-heating phase in order to keep injected fuel flow heated enough until combustion stability. Depending on the environment temperature, if the fuel injection flow is not kept heated enough, vehicle will shut down after seconds. Moreover, adequate injected fuel flow temperature during post-crank phase is essential for guaranteeing acceptable pollutant emission level, considering that starting the vehicle under cold temperature tends to be considerable more aggressive in terms of pollutant emissions than starting vehicle when its engine temperature is already stabilized.

\section{VEHICLE TESTS RESULTS}

Vehicle tests were done under temperatures of $-5^{\circ} \mathrm{C}, 0^{\circ} \mathrm{C}$ and $10^{\circ} \mathrm{C}$. For these technology comparative tests, same pre-heating time was used in both parts when at same temperature. Lower temperatures mean longer pre-heating times. All used lead-times were the same present at vehicle original calibration.

As showed on figure 7 , at $-5^{\circ} \mathrm{C}(23 \mathrm{~F})$ self-controlled CSS presented 1.25 second average starting time with 0.14second deviation. Baseline CSS presented 1.52second average starting time with 0.10 second deviation. It means that a starting time reduction was achieved with higher standard time variation. At this temperature, starting procedure with ethanol is a real challenge and variations can be found in both systems.

\section{Start Time Results $-5^{\circ} \mathrm{C}$}

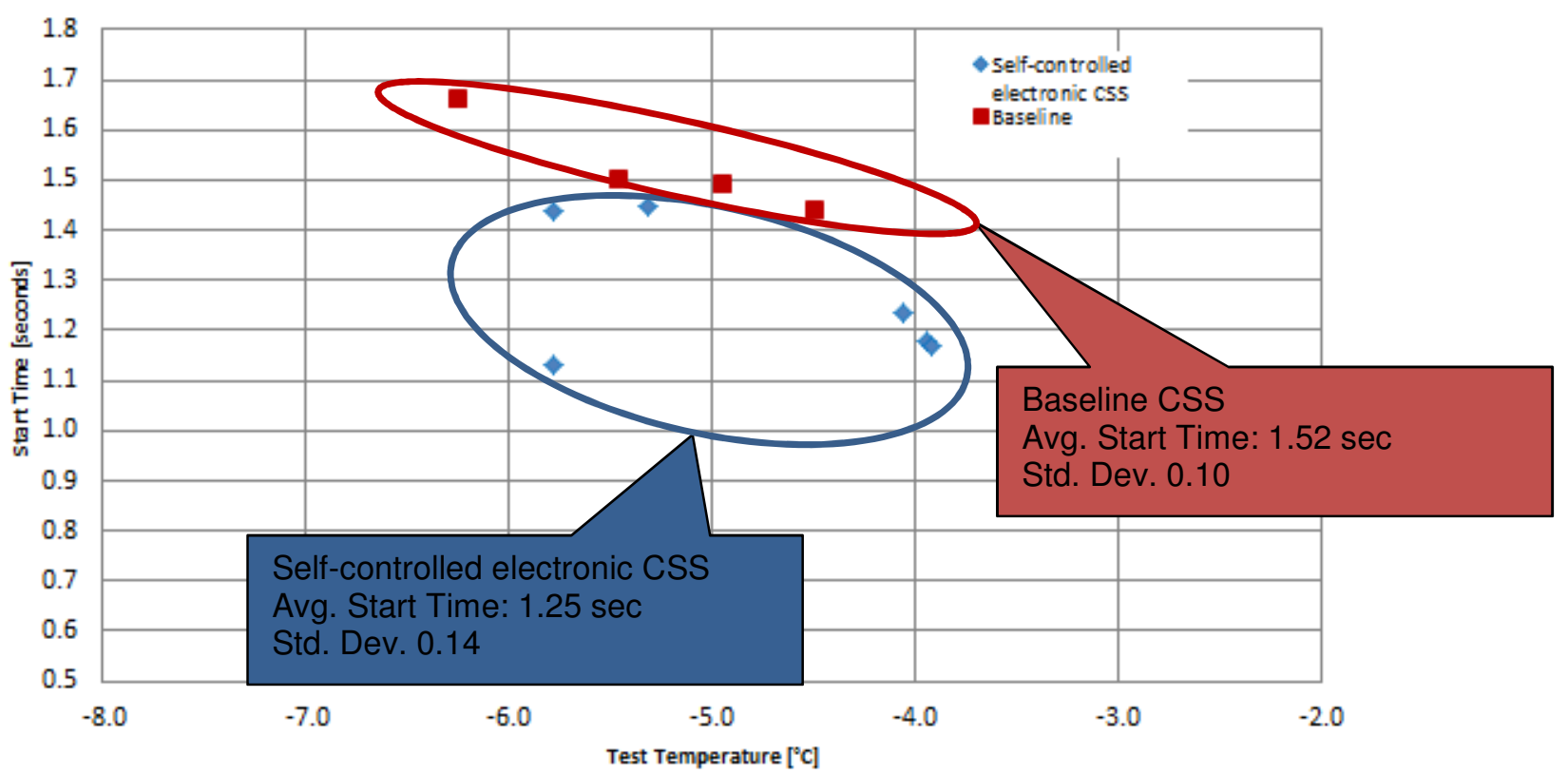

Figure 7. Comparative Tests at $-5^{\circ} \mathrm{C}$ 
At $0^{\circ} \mathrm{C}(32 \mathrm{~F})$, test results are presented on figure 8 . It shows a clear reduction on the average starting time (around 17\%) of the self-controlled electronic CSS compared to the baseline heated system. Standard deviation is similar on both systems.

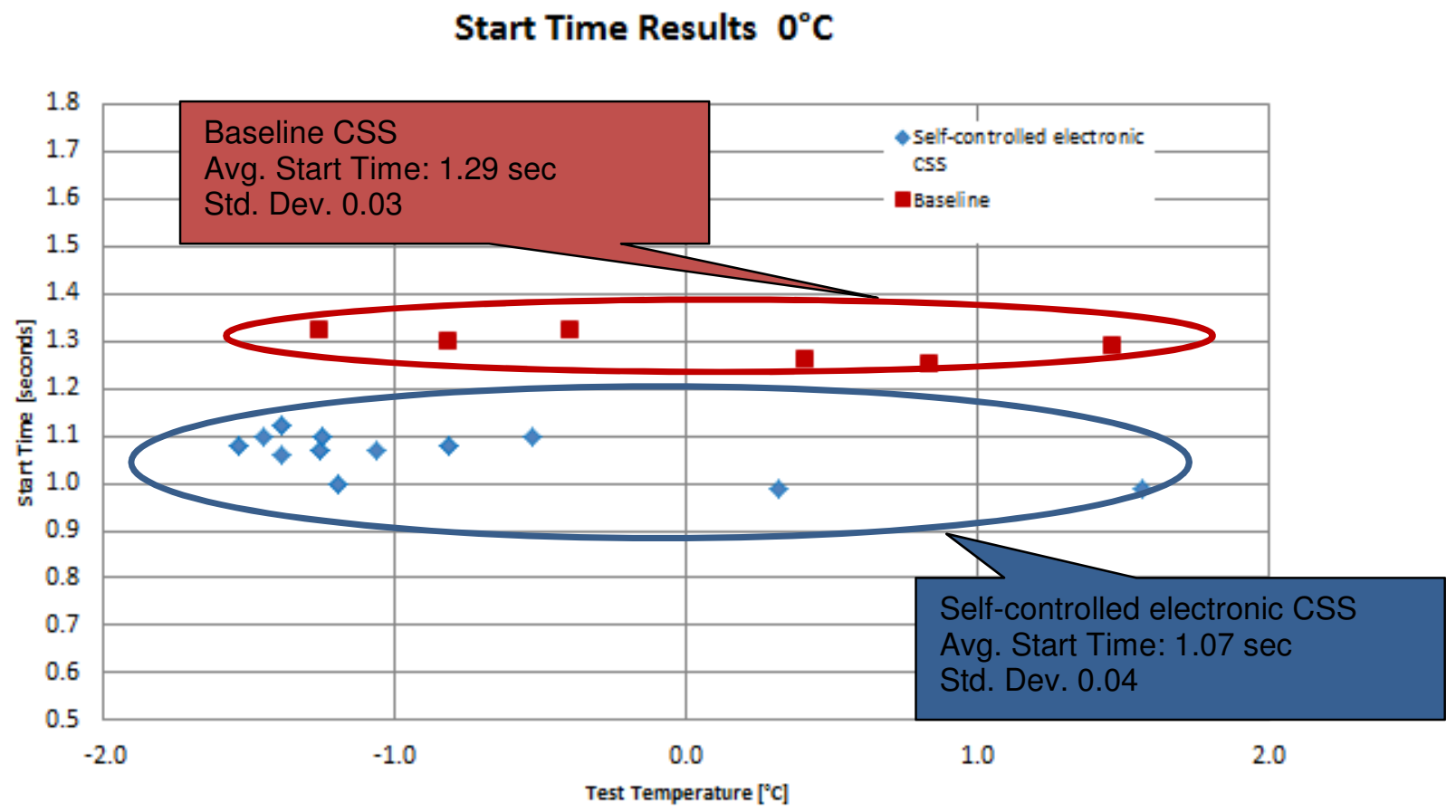

Figure 8. Comparative Tests at $0^{\circ} \mathrm{C}$

Self-controlled electronic CSS improvements can also be found at $10^{\circ} \mathrm{C}(50 \mathrm{~F})$. See figure 9. Average starting time is reduced in $12 \%$ and similar standard deviation is found, when compared to baseline system.

Start Time Results $10^{\circ} \mathrm{C}$

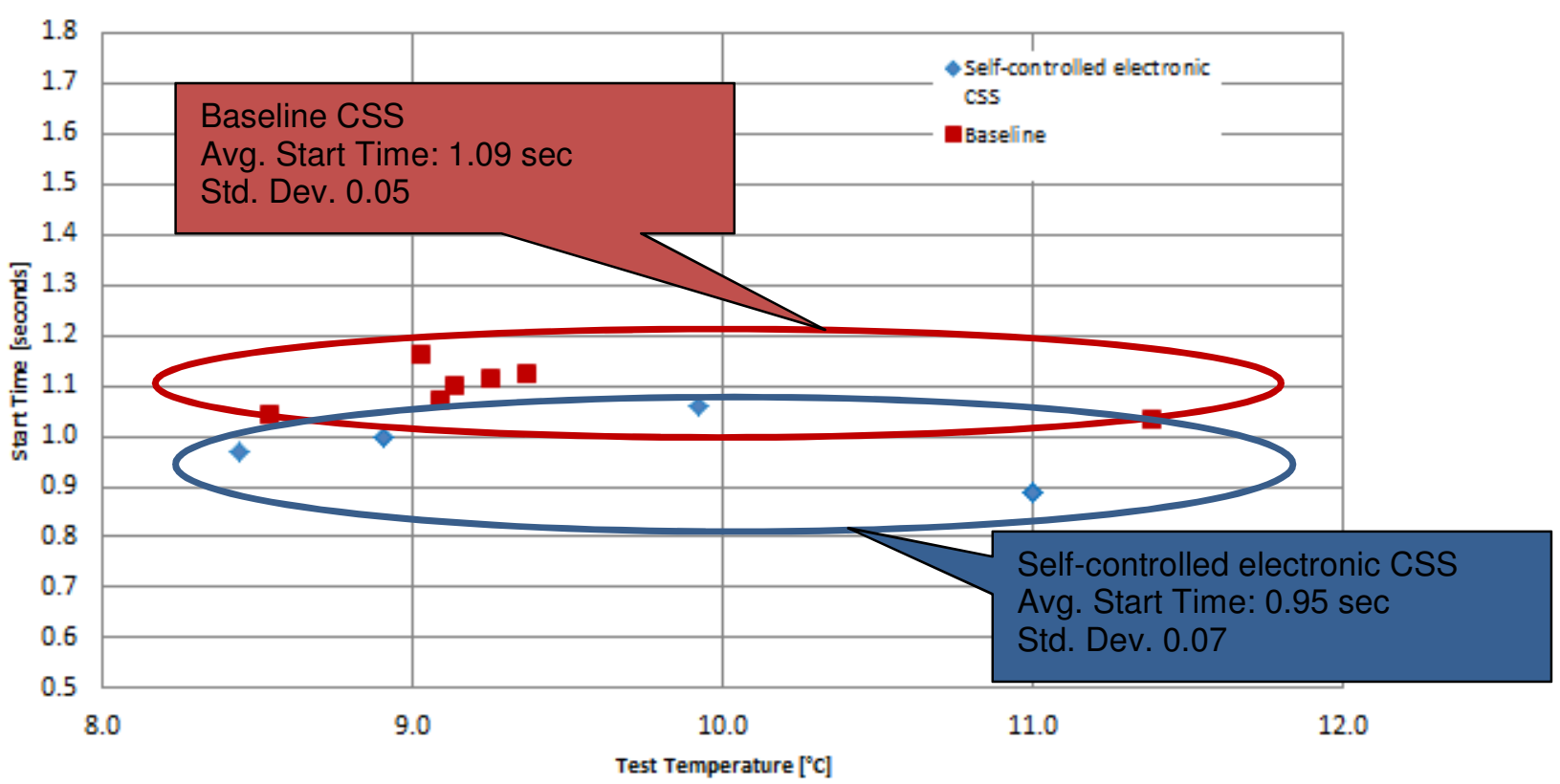

Figure 9. Comparative Tests at $10^{\circ} \mathrm{C}$ 


\section{CONCLUSIONS}

At vehicle tests, self-controlled electronic cold start system presented improved performance compared to baseline system. Starting time reduction from $12 \%$ to $17 \%$ was obtained keeping same components interface and calibration, eliminating the obligation of electronic control devices and allowing simpler vehicle calibration. This higher fuel heating transfer efficiency can be used in different ways, depending on customer needs. If target is to keep same start time, vehicle calibration can be improved to reduce pre-heating time. If target is to keep preheating time, start time can be improved.

Overall engine coolant temperature variation in the tests is within a three Fahrenheit range. Even with this variation, self-controlled electronic cold start system has proved to be robust with similar dispersion than baseline at $0^{\circ} \mathrm{C}$ and $10^{\circ} \mathrm{C}$. Baseline system, with additional heating control unit, does a closed loop control and adjusts pre-heating time according to previous determined calibration. At self-controlled electronic cold start system, pre-heating time was adjusted in a fixed lead-time reference at same temperature region, as there is no additional electronic control and fine temperature tuning is done by PTC thermistor.

Furthermore, due to self-controlled CSS high thermal efficiency, warmer fuel could lead to lower injected fuel mass, what is a potential for emission reductions. Current regulation allows unburned ethanol discount at final emission numbers. If this statement changes, selfcontrolled electronic CSS vehicle tests (not included in this paper) showed $\mathrm{HC}$ and $\mathrm{CO}$ reduction (about 32\%) and it can be used as alternative.

In this way, technology proved to bring technical advantages to ethanol cold start phase and represents an alternative for automotive market in order to improve next flexible fueled vehicles generations.

\section{REFERENCES}

[1] Nakajima S., "Enhancement of Low-temperature Combustion in Flexible Fuel Vehicle (FFV) Engine,” Honda R\&D Technical Review,October,2010,p.131-138.

[2] Heater L, MacLean, Lester B. Lave, "Evaluating automobile fuel/propulsion system technologies," Progress in Energy and Combustion Science, 2003.29:1-69, 2003, doi:10.1016/S0360-1285(02)00032-1.

[3] A. Günther,K.-E. Wirth, "Evaporation phenomena in superheated atomization and its impact on the generated spray," International Journal of Heat and Mass Transfer, doi:10.1016/j.ijheatmasstransfer.2013.05.034 


\section{DEFINITIONS/ABREVIATIONS}

ACT

CSS

ECT

ECU

Flash point

PTC

RPM

Time_ON

VBAT

VCT
Air charge temperature

Cold start system

Engine coolant temperature

Electronic control unit

Low temperature at which vapor above a volatile combustible substance ignite in air when exposed to flame

Positive temperature coefficient

Engine speed (Revolutions per minute)

How long the cold start system is on

Battery voltage

Variable Camshaft Timing 